\title{
Evaluation of irrigation water salinity and leaching fraction on the water productivity for crops
}

\author{
Songrui Ning, Beibei Zhou*, Quanjiu Wang, Wanghai Tao \\ (State Key Laboratory of Eco-hydraulics in Northwest Arid Region of China, Xi'an University of Technology, Xi'an 710048, China)
}

\begin{abstract}
In arid and semi-arid irrigated croplands, the excessive accumulation of soluble salts in the root zone is an extensive problem that seriously limits crop yield and water productivity (WP). To avoid affects the yield potential of crops, the application of extra irrigation for leaching of excessive salts from the root zone was required. Quantitative knowledge of effects of the irrigation water salinity and leaching fraction (LF) on the relative yield (RY) and the unit water productivity of crop evapotranspiration $\left(\mathrm{UWP}_{\mathrm{ET}}\right)$ and the unit water productivity of irrigation water $\left(\mathrm{UWP}_{\mathrm{I}}\right)$ were becoming gradually important. This article provided theoretical models for estimating the UWPs $\left(\mathrm{UWP}_{\mathrm{ET}}\right.$ and $\left.\mathrm{UWP}_{\mathrm{I}}\right)$ and optimizing leaching fraction according to irrigation water salinity. In the present study, eight levels of irrigation water salinity $(E C w=0.25,0.50$, $0.75,1,2,3,4$, and $5 \mathrm{dS} / \mathrm{m}$ ) and 39 levels of LF values ranging from 0.04 to 0.80 were set and tested to assessing their effects on the RY and UWPs for four typical crops (barley, bean, wheat, and maize) with different salt tolerance levels. Almost every curve determined between the UWPs and LFs for the four crops had an inflection point. It was indicated that the $U_{W P}$ and $U_{W P}$ could be maximized by optimizing the LF under different irrigation water salinities. Furthermore, the linear regression relationships were established to estimate the maximum values of UWPs and their corresponding optimal LFs for four crops by using the irrigation water salinity. Moreover, the theoretical models for estimating the UWPs were validated by data of wheat from previous literature, and the models could be suitable with acceptable relative errors when LFs ranging from 0.07 to 0.17 .
\end{abstract}

Keywords: irrigation water salinity, leaching fraction, salt-tolerant crop, salt stress, crop yield, water productivity DOI: $10.25165 /$ j.ijabe.20201301.5047

Citation: Ning S R, Zhou B B, Wang Q J, Tao W H. Evaluation of irrigation water salinity and leaching fraction on the water productivity for crops. Int J Agric \& Biol Eng, 2020; 13(1): 170-177.

\section{Introduction}

Agricultural production is the largest consumer of water throughout the world. The limited availability of water resources, especially the scarcity of fresh water resources, hinders sustainable agricultural development in arid and semi-arid areas with irrigated soils ${ }^{[1,2]}$. To address the problems caused by shortages of fresh water, lower quality (saline) waters are important irrigation water resources for overcoming drought and maintenance of crop yields ${ }^{[3,4]}$. The standard strategies for using marginal quality waters focused on avoiding reductions in the growth or yield of crops, while also aimed at preventing the excessive accumulation of soluble salts and maintaining the salinity level in the root zone $^{[5-8]}$. However, achieving the maximum yield is frequently not the optimal strategy with respect to water productivity (WP), particularly where water resources are limited ${ }^{[9,10]}$.

Wheat, maize and barley are three widely cultivated staple cereals, and beans that high in protein and soluble fiber are also used as important human food. Many studies have investigated

Received date: 2019-03-29 Accepted date: 2019-12-04

Biographies: Songrui Ning, $\mathrm{PhD}$, research interests: soil physics, soil water-salt transport, Email: ningsongrui@163.com; Quanjiu Wang, PhD, Professor, research interests: soil physics, soil and water management, Email: wquanjiu@163.com; Wanghai Tao, Master, research interests: soil physics, Email: xautsoilwater@163.com.

*Corresponding author: Beibei Zhou, $\mathrm{PhD}$, Professor, research interests: soil physics, water saving irrigation. Institute of Water Resources and Hydro-electric Engineering, Xi'an University of Technology, Xi'an 710048, China. Tel: +86-18092566660, Email: happyangle222@aliyun.com. irrigation and cultivation with saline water to produce these four typical crops ${ }^{[3,4,11,12]}$. Wang et al. ${ }^{[13]}$ indicated that irrigation with saline water at concentrations below $3 \mathrm{~g} / \mathrm{L}$ reduced the crop yield, and long-term irrigation with saline water significantly decreased the yield. The yield and water use efficiency of maize decreased as the salinity of the irrigation water increased ${ }^{[3]}$. Hamdy et al. ${ }^{[11]}$ applied supplemental irrigation to wheat and barley during flowering and seed formation using limited amounts of brackish water with 3 to $9 \mathrm{dS} / \mathrm{m}$, and there were mean reductions of $21 \%$ in the barley yield and $25 \%$ in the wheat yield compared to the control that irrigated with fresh water.

Irrigation with saline water affects the yield in cereals and the soil environment (e.g., soil salinization) because of the salts that contain in water ${ }^{[3,4]}$. Therefore, appropriate irrigation management practices are required when saline water is used for irrigation, leaching salts out of the root zone in order to improve the crop yield and WP. However, the yield does not simply increase with the increase of irrigation amount, which leads to the irrigation water used inefficiently. Besides, the application of more water than requirement for leaching salts and crop evapotranspiration $\left(\mathrm{ET}, \mathrm{m}^{3} / \mathrm{hm}^{2}\right)$ can still maintain the maximum yield, but the leaching of pesticides, nutrients, and trace elements may also increase the risk of environmental contamination ${ }^{[6,14]}$. Thus, the maximum crop yield and WP could be optimized by adjusting irrigation water depth (included leaching water depth). The leaching fraction (LF) is defined as the fraction of the applied irrigation water $\left(\mathrm{I}, \mathrm{m}^{3} / \mathrm{hm}^{2}\right)$ that passes through the entire rooting depth and drains $\left(\mathrm{D}, \mathrm{m}^{3} / \mathrm{hm}^{2}\right)$ beyond the root zone under 
steady-state conditions ${ }^{[15]}$. As an indicator of the degree to which salts are leached from the root zone, LF is the simplest form of the soil water and salt balance in the root zone ${ }^{[16]}$. Moreover, the leaching requirement (LR) is a specific quantitative value defined as the minimum LF required over a growing season for a particular quality of water in order to achieve the maximum yield for a given crop $^{[15]}$. Clearly, a reliable and accurate LR value is vital for the efficient application of irrigation water ${ }^{[6]}$. Underestimating the LR will result in salt accumulation in the root zone and yield reductions, whereas overestimating the LR will lead to excessive water utilization and nutrient removal, with detrimental environmental effects on groundwater or drainage water, and declines in the crop water productivities. In many studies, the terms LR and LF are generally used interchangeably ${ }^{[15,17]}$.

Researches discussed the applications of steady-state and transient-state models, and both types' models have their place in agricultural water management and salinity assessments ${ }^{[8,17,18]}$. Corwin et al. ${ }^{[17]}$ evaluated the appropriateness of the steady-state approach for estimating LR compared with the transient approach, and showed that the calculated LR was lower using the transient method than using the steady-state method. Letey et al. ${ }^{[15]}$ evaluated soil salinity leaching requirement guidelines and concluded that the current guidelines overestimate the LR compared with transient-state and steady-state analyses. Compared with steady-state and transient analyses, Corwin et al. ${ }^{[6]}$ pointed out that transient models do not directly calculate LR, and are not user-friendly as the input parameters are not available and easy to establish. Thus, the steady-state models can be recommended as a first and quick approximation to decide the appropriateness of water for irrigation ${ }^{[6]}$. The steady state was a reasonable approximation over sufficiently long time periods (e.g., more than one season), and they have relatively modest data requirements. Many studies have used them to evaluate the effects on plant growth and the yield response of the LF and irrigation water salinity in order to enhance plant growth ${ }^{[18-23]}$. Under a given irrigation water salinity, a suitable LF value can be used to increase relative yield and maximize the WP for irrigation water ${ }^{[24]}$, but the computational method was not verified. However, few studies have considered whether irrigation water quality can be further used to estimate crop relative yield and maximum value of unit water productivities for crop evapotranspiration with the corresponding optimal value of leaching fractions.

The objective of this study is to propose a method for estimating unit water productivities for crop evapotranspiration, and maximizing unit water productivities for crop evapotranspiration and irrigation water (UWPs) by optimizing leaching fraction under different irrigation water salinities. The calculation methods for UWPs were verified by field experiment data from the literature.

\section{Material and methods}

\subsection{Theoretical analysis}

\subsubsection{WP}

WP refers to the quantity of crop production per unit water used, where the unit water use varies with respect to different scales $^{[25]}$. The WP for crop ET $\left(W P_{E T}\right)$ and WP for irrigation water $\left(W P_{I}\right)$ are expressed in terms of the grain yield $\left(Y, \mathrm{~kg} / \mathrm{hm}^{2}\right)$ divided by the crop ET $\left(\mathrm{m}^{3} / \mathrm{hm}^{2}\right)$ or the irrigation water used $(I$, $\mathrm{m}^{3} / \mathrm{hm}^{2}$ ), respectively.

$$
\begin{gathered}
W P_{E T}=\frac{Y}{E T} \\
W P_{I}=\frac{Y}{I}
\end{gathered}
$$

\subsubsection{Unit WP (UWP)}

In agronomy, the crop salt tolerance is defined as the crop relative yield (RY, \%) at a given soil salinity compared with the yield from a non-saline soil. The soil salinity refers to the mean salinity in the root zone and is expressed as the electrical conductivity of the soil saturated paste extract $(E C e, \mathrm{dS} / \mathrm{m})$. For a specific crop, the crop relative yield-salinity relationships is calculated as follows ${ }^{[26]}$ :

$$
R Y=100-b \times(E C e-a)
$$

where, $a$ is the threshold soil salinity (the maximum allowable soil salinity for a crop without a yield reduction, $\mathrm{dS} / \mathrm{m}$ ) and $b$ is the slope expressed as the yield loss in $\%$ per unit increase in the soil salinity beyond the threshold salinity level $(1 \mathrm{dS} / \mathrm{m})$. The values of the threshold $a$ and slope $b$ were obtained from the Maas-Hoffman model ${ }^{[26]}$.

More soluble salt is added to the soil during irrigation treatment with saline water. The accumulation of salt in the soil profile to an equilibrium concentration predominantly depends on the LF and the applied water (AW) quality after much successive irrigation of saline water ${ }^{[6,8]}$. The average steady-state soil salinity $(E C e, \mathrm{dS} / \mathrm{m})$ reflects the changes due to long-term saline water usage, not short-term changes that might occur within a season or between irrigation treatments, and it can be estimated from the irrigation water salinity $(E C w, \mathrm{dS} / \mathrm{m})$ and relative concentration factor $F c^{[27]}$, as follows.

$$
E C e=E C w \times F C
$$

A higher LF results in the accumulation of less salt in the root zone than a lower LF, and the commonly used LF values range from 0.05 to $0.80^{[15]}$. The relationship between concentration factor $F C$ and LF is as follows ${ }^{[24]}$.

$$
F c=\frac{1+L F}{3 L F}
$$

The AW needed to meet both the crop ET demand and leaching requirement is:

$$
A W=\frac{E T}{1-L F}
$$

The total AW depth was also assessed based on the water demand for irrigation to meet the crop water consumption and salt leaching requirements, which can be expressed as the following Equation (7).

$$
A W=I+D=I \times(1+L F)
$$

Equations (6) and (7) are expressed in terms of the absolute field AW and crop ET values, and the irrigation amount. They can be stated in relative terms, which are particularly useful for transferring relationships between geographical areas with irrigation events under different climates, e.g.:

$$
\begin{aligned}
& \frac{A W}{E T}=\frac{1}{1-L F} \\
& \frac{A W}{I}=1+L F
\end{aligned}
$$

where, $A W / E T$ is defined in this study as the relative crop ET (RET in $\%$ ) and $R E T>1$ generally denotes deep percolation water beyond the root zone. $A W / I$ is defined as the relative irrigation depth $(R I$ in $\%)$ and $R I>1$ denotes that deep water percolation occurs. 
Substitute Equations (3) and (8) into Equation (1) yields the UWP for crops ET $\left(U W P_{E T}\right)$. UWP $\mathrm{UT}_{\mathrm{ET}}$ is defined as the ratio of the crop RY relative to the crop RET in this study, and it can be rewritten as follows,

$$
U W P_{E T}=\frac{R Y}{R E T}=R Y \times(1-L F)
$$

The UWP for irrigation water $\left(\mathrm{UWP}_{\mathrm{I}}\right)$ was determined by Equation (11) ${ }^{[24]}$,

$$
U W P_{I}=\frac{R Y}{R I}=\frac{R Y}{1+L F}
$$

\subsection{Irrigation water quality and crops}

In irrigated areas, the salt that accumulates in the root zone often originates from the salt in the AW. A classification of different saline sources is given in Table 1 in terms of the electrical conductivity, which is the major quality factor that generally limits the use of saline waters for crop production.

\begin{tabular}{|c|c|c|c|}
\hline Water class & $\begin{array}{l}\text { Electrical conductivity } \\
\qquad / \mathrm{dS} \cdot \mathrm{m}^{-1}\end{array}$ & Type of water & $\begin{array}{c}\text { Effects on crop } \\
\text { water availability }\end{array}$ \\
\hline Non saline & $<0.75$ & $\begin{array}{l}\text { Drinking and } \\
\text { irrigation water }\end{array}$ & None \\
\hline Slightly saline & $0.75-3.0$ & Irrigation water & Slight to moderate \\
\hline $\begin{array}{l}\text { Moderately } \\
\text { saline }\end{array}$ & $>3.0$ & $\begin{array}{l}\text { Primary drainage water } \\
\text { and groundwater }\end{array}$ & Severe \\
\hline
\end{tabular}

Table 1 Classification of saline waters ${ }^{[28]}$

In addition, the salt tolerance levels of crops are presented in Table 2 where they can be divided into four classes: tolerant, sensitive, moderately tolerant, and moderately sensitive ${ }^{[26]}$. Normally, the threshold $a$ and slope $b$ for a crop remain within one rating class. Crops (barley, bean, wheat, and maize) are the main food crops grown on arable land throughout the world, and the yield from cereals (e.g. barley, wheat, and maize) comprises $57 \%$ of global food production ${ }^{[29,30]}$. The tolerance of salt for the four typical crops (i.e., the salinity ratings are tolerant for barley, sensitive for bean, moderately tolerant for wheat, and moderately sensitive for maize) ranges from tolerant to sensitive, as shown in Table 2 .

Table 2 Salt tolerance levels of four typical crops (barley, bean, wheat, and maize $)^{[26,31,32]}$

\begin{tabular}{lccc}
\hline \multirow{2}{*}{ Typical crops } & \multicolumn{2}{c}{ Salt tolerance parameters } & \\
\cline { 2 - 3 } & $\begin{array}{c}\text { Threshold } \\
/ \mathrm{dS} \cdot \mathrm{m}^{-1}\end{array}$ & $\begin{array}{c}\text { Slope per } \\
\left(\mathrm{dS} \cdot \mathrm{m}^{-1}\right) / \%\end{array}$ & Rating \\
\hline Barley (Hordeum vulgare) & 8 & 5 & Tolerant \\
Bean (Leguminosae) & 1 & 19 & Sensitive \\
Wheat (Triticum aestivum) & 6 & 7.1 & Moderately tolerant \\
Maize (Zea mays) & 1.7 & 12 & Moderately sensitive \\
\hline
\end{tabular}

In this study, the effects of eight salinity levels in irrigation water $(\mathrm{ECw}=0.25,0.50,0.75,1,2,3,4$, and $5 \mathrm{dS} / \mathrm{m})$ and four typical crops comprising barley, bean, wheat, and maize under LF values ranging from 0.04 to 0.80 with increments of 0.02 on the RY and UWPs $\left(\mathrm{UWP}_{\mathrm{ET}}\right.$ and $\left.\mathrm{UWP}_{\mathrm{I}}\right)$ were tested. Optimization was then conducted to maximize the UWPs and the corresponding LFs under irrigation water with a given salinity.

All the computer programming was done with EXCEL 2013 (Microsoft Corporation, Redmond, Washington). The linear regression was performed with the statistical software SigmaPlot 10.0 software (Systat Software, San Jose, CA) for windows. Graphical and quantitative analyses of the data were carried out using OriginPro 9.0 program (OriginLab Corporation, Northampton, MA).

\section{Results and discussion}

\subsection{Effects of irrigation water salinity and $\mathrm{LF}$ on crop relative yields}

Salt tolerance data of four typical crops (i.e. barley, bean, wheat, and maize) and relative yield-salinity relationships were quoted from Maas and Hoffman ${ }^{[26]}$. Figure 1 clearly shows the effects of the irrigation water salinity and LF on the crop relative yields. Under irrigation water with a given electrical conductivity, the relative yields improved gradually to the maximum RY (i.e., $\mathrm{RY}=100 \%$ ) as the LF increased, where the maximum RY for each crop had an optimal value for LF (referred to as $\mathrm{LF}_{1}$ ). The RY of the crop remained unchanged when the $L F$ value exceeded $L F_{1}$. Hoffman et al. ${ }^{[33]}$ reported similar trends for wheat, sorghum, and lettuce. Under the same RY conditions, more salt accumulated in the crop root zone and the values of the leaching requirement clearly improved as the irrigation water salinity increased, and thus the required amount of AW increased. The relationship between LF and RY was nonlinear and the RY decreased with increasing salinity of irrigation water and decreasing LF, especially the LF value less than $\mathrm{LF}_{1}$. Dudley et al. ${ }^{[14]}$ also reported similar results. Under a given LF, the salt stress gradually increased and the RY decreased significantly as the irrigation water salinity increased. For instance, when the LF value was 0.16 and the irrigation water had electrical conductivities of $0.25,0.50,0.75,1,2,3,4$, and $5 \mathrm{dS} / \mathrm{m}$, the RY for maize reached $100 \%, 100 \%, 98.65 \%, 91.40 \%$, $62.40 \%, 33.40 \%, 4.40 \%$, and 0 , respectively.

Crops with different levels of salinity tolerance resulted in diverse LR values. Under a given irrigation water quality, the corresponding optimal $\mathrm{LF}\left(\mathrm{LF}_{1}\right)$ increased when the salt tolerance levels of the crops all reached the same RY as the crop's salt tolerance capacity decreased. In particular, the leaching requirement $\left(\mathrm{LF}_{1}\right)$ values were $0.10,0.80,0.30$, and 0.62 according to the maximum RYs of the four crops, i.e., barley (salinity rating is tolerant), bean (sensitive), wheat (moderately tolerant), and maize (moderately sensitive), respectively, under a given irrigation water salinity of $2 \mathrm{dS} / \mathrm{m}$. Moreover, the RY values for barley, bean, wheat, and maize were $100 \%, 27.17 \%, 48 \%$, and $32.40 \%$, respectively, with an $L F$ value of 0.16 and irrigated water electrical conductivity of $2 \mathrm{dS} / \mathrm{m}$. These results suggest that barley (or other crops with high salt tolerance) could be used instead of bean (or other moderately sensitive salt-tolerant crops) to obtain the highest relative yield in areas with limited water supplies.

In addition, the leaching requirement was influenced by the salinity of the irrigation water and crop sensitivity ${ }^{[14]}$. The optimal values of leaching fractions $\left(\mathrm{LF}_{1}\right)$ under different irrigation water qualities for each crop were shown in Figure 2. For example, when the applied irrigation water had electrical conductivities of $0.25,0.50,0.75,1,2,3,4$, and $5 \mathrm{dS} / \mathrm{m}$, the maximum relative yield for barley corresponded to optimal LF values $\left(\mathrm{LF}_{1}\right)$ of $0.02,0.04,0.04,0.06,0.10,0.16,0.20$, and 0.28 , respectively. Figure 2 also illustrated the relatively strong linear correlations with irrigation water quality for each crop. The regression equations obtained by the linear regression method were shown in Table 3. It is easy to measure the salinity of irrigation water, and the optimal values of $\mathrm{LF}_{1}$ can be estimated rapidly and accurately based on the linear regression equations for each crop. 

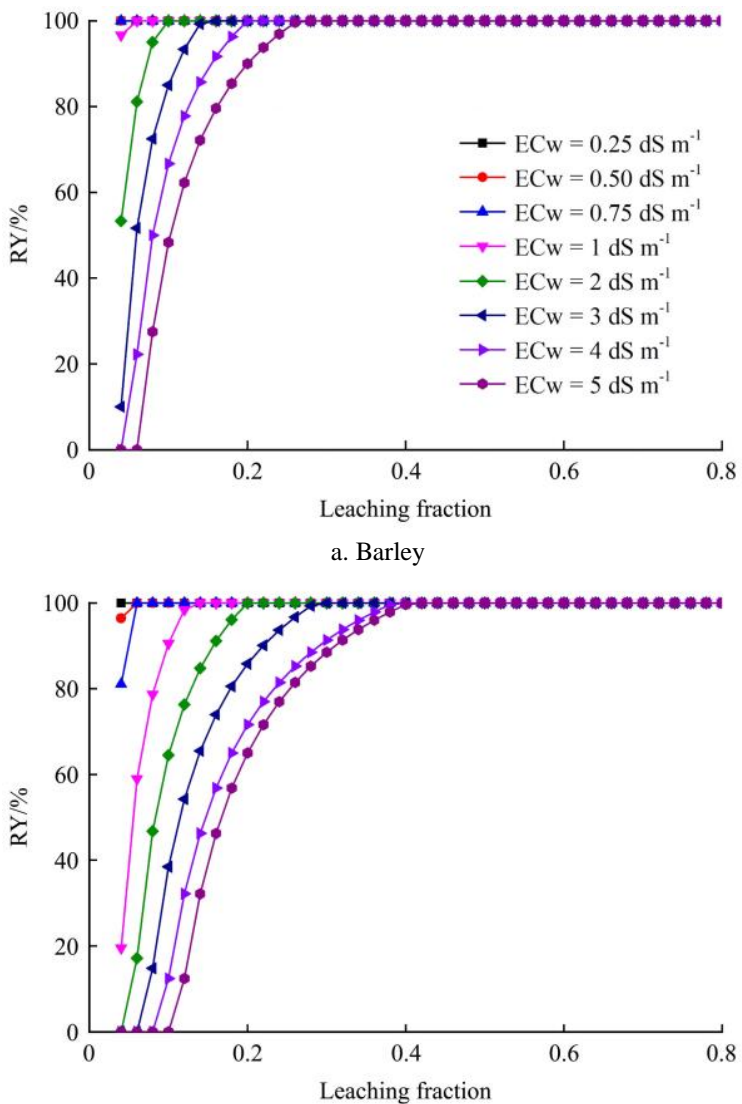

c. Wheat
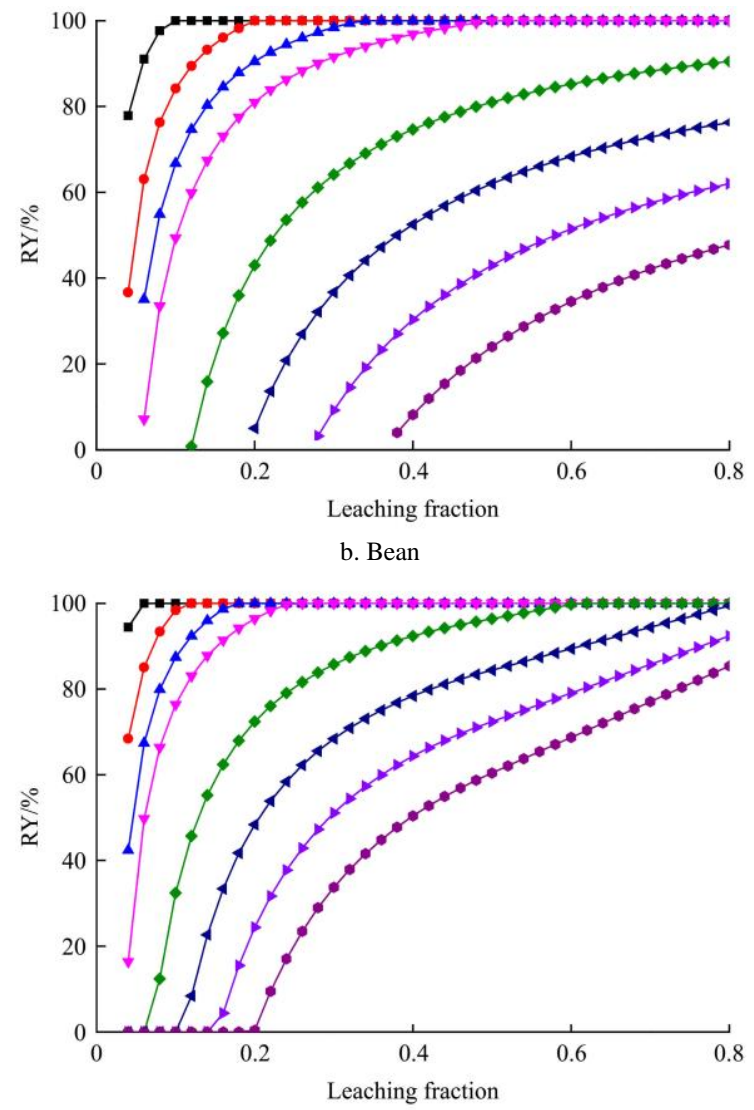

d. Maize

Figure 1 Relative yield $(R Y)$ for crops and leaching fraction $(L F)$ under different irrigation water salinities $(E C w=0.25,0.50,0.75,1,2,3,4$, and $5 \mathrm{dS} / \mathrm{m})$

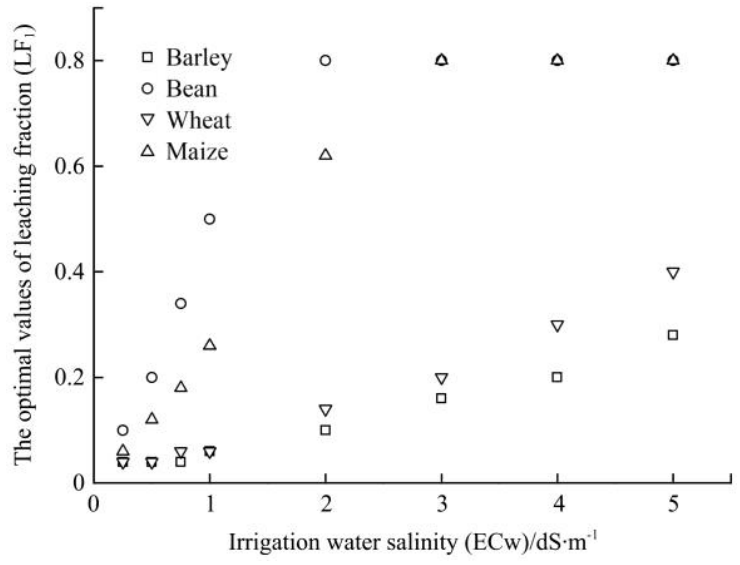

Figure 2 Optimal leaching fractions $\left(\mathrm{LF}_{1}\right)$ under different irrigation water salinities for barley, bean, wheat, and maize

Table 3 Regression equations between the optimal leaching fractions $\left(\mathrm{LF}_{1}\right)$ and irrigation water salinity $(\mathrm{ECw}, \mathrm{dS} / \mathrm{m})$ for barley, bean, wheat, and maize

\begin{tabular}{ccc}
\hline Typical crops & Regression equation & Note \\
\hline Barley & $\mathrm{LF}_{1}=0.011-0.051 E C w$ & $0.25 \leq E C w \leq 5$ \\
$R^{2}=0.981 \quad p<0.001$ & \\
\hline Hordeum vulgare $)$ & $\mathrm{LF}_{1}=0.026+0.402 E C w$ & $0.25 \leq E C w \leq 2$ \\
$R^{2}=0.966 \quad p<0.001$ & $2<E C w \leq 5$ \\
\hline Bean (Leguminosae) & $\mathrm{LF}_{1}=0.8 \quad R^{2}=1 \quad p<0.001$ & $0.25 \leq E C w \leq 5$ \\
\hline Wheat & $\mathrm{LF}_{1}=-0.002-0.076 E C w$ \\
$R^{2}=0.981 \quad p<0.001$ & $0.25 \leq E C w \leq 3$ \\
\hline Maize (Zea mays) & $\mathrm{LF}_{1}=-0.015+0.284 E C w$ & $3<E C w \leq 5$ \\
\hline$R^{2}=0.982 \quad p<0.001$ &
\end{tabular}

3.2 Effects of the irrigation water salinity and LF on the UWP for crops evapotranspiration

Figure 3 shows the relationships between the $\mathrm{UWP}_{\mathrm{ET}}$ and the $\mathrm{LF}$ values under different irrigation water qualities for the four crops (barley, bean, wheat, and maize). In general, the $\mathrm{UWP}_{\mathrm{ET}}$ all increased to a certain value and then decreased as the LF increased.

Almost every curve calculated between the $\mathrm{UWP}_{\mathrm{ET}}$ and LF for the four crops had an obvious inflection point, which denoted the maximum value of $\mathrm{UWP}_{\mathrm{ET}}$ (referred to as $\mathrm{UWP}_{\mathrm{ET}}^{\prime}$ ) with the corresponding optimal value of $\mathrm{LF}\left(\mathrm{LF}_{2}\right)$. Thus, the $\mathrm{UWP}_{\mathrm{ET}}$ could be maximized by the optimized LF under the given irrigation water quality. When the $\mathrm{LF}$ value was less than or greater than the $\mathrm{LF}_{2}$ value, the $\mathrm{UWP}_{\mathrm{ET}}$ all exhibited upward or downward trends, respectively, thereby indicating that the AW was inefficient and unfavorable for saving agricultural water.

As the irrigation water quality increased, the $\mathrm{UWP}_{\mathrm{ET}}^{\prime}$ values decreased and the corresponding optimal $\mathrm{LF}\left(\mathrm{LF}_{2}\right)$ increased gradually. For example, when the applied irrigation water had electrical conductivities of $0.25,0.50,0.75,1,2,3,4$, and $5 \mathrm{dS} / \mathrm{m}$, the values of UWP' $_{\text {ET }}^{\prime}$ for barley were $98 \%, 96 \%, 96 \%, 94 \%, 90 \%, 85.39 \%$, $80 \%$, and $73.72 \%$, respectively, which corresponded to the optimal $\mathrm{LF}_{2}$ values of $0.02,0.04,0.04,0.06,0.1,0.14,0.18$, and 0.26 .

Under different irrigation water qualities, the crops with high salt tolerance (e.g. barley) could achieve the maximum UWP' values and the crops with low salt tolerance (e.g., bean) attained the minimum UWP' ${ }_{\mathrm{ET}}$ values. In contrast to the UWP' ${ }_{\mathrm{ET}}$ values obtained for barley under different irrigation water qualities, lower

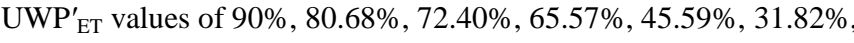
$21.58 \%$, and $13.82 \%$ were achieved for bean, and the corresponding $\mathrm{LF}_{2}$ values were larger at $0.10,0.16,0.20,0.240 .34$, 
$0.44,0.52$ and 0.60 , respectively. Under the same irrigation water quality and LF conditions, the UWP' ${ }_{\mathrm{ET}}$ values decreased as the salt tolerance capacity of the crops decreased.

The UWP' ${ }_{\text {ET }}$ values and their corresponding optimal LFs $\left(\mathrm{LF}_{2}\right)$ under different irrigation water qualities are presented in Figure 4. In order to facilitate their application in agricultural production and to guide irrigation practices, the highly significant relationships estimated between the values of $\mathrm{UWP}_{\mathrm{ET}}^{\prime}$ and the irrigation water quality for each crop were approximated by linear equations (Figure 4). Moreover, the obvious linear regression relationships between $\mathrm{LF}_{2}$ and the irrigation water quality for each crop are shown in Figure 4. These relationships provided simple methods for rapidly confirming and effectively improving the $\mathrm{UWP}_{\mathrm{ET}}$. In general, in order to achieve the same $\mathrm{UWP}_{\mathrm{ET}}$ value, the required irrigation water quality by different crops increases as the salt tolerance capacity of the crops decreases. For example, to obtain $\mathrm{UWP}_{\mathrm{ET}}$ values greater than $80 \%$, the electrical conductivity of the irrigation water should not exceed $4 \mathrm{dS} / \mathrm{m}$ for barley with a high tolerance of salinity and $0.75 \mathrm{dS} / \mathrm{m}$ for bean with sensitivity tolerance of salinity, respectively.

\subsection{Effects of irrigation water salinity and LF on the UWP for irrigation water}

Similarly, the relationship between UWP for irrigation water $\left(\mathrm{UWP}_{\mathrm{I}}\right)$ and $\mathrm{LF}$ under each given irrigation water quality had an inflection point. The $\mathrm{UWP}_{\mathrm{I}}$ values for each crop (barley, bean, wheat, and maize) increased but then decreased as LF increased (Figure 5). The maximum $\mathrm{UWP}_{\mathrm{I}}$ value $\left(\mathrm{UWP}_{\mathrm{I}}^{\prime}\right)$ with the corresponding optimal $\mathrm{LF}\left(\mathrm{LF}_{3}\right)$ and the $\mathrm{UWP}_{\mathrm{I}}$ could also be optimized based on LF under different irrigation water qualities.
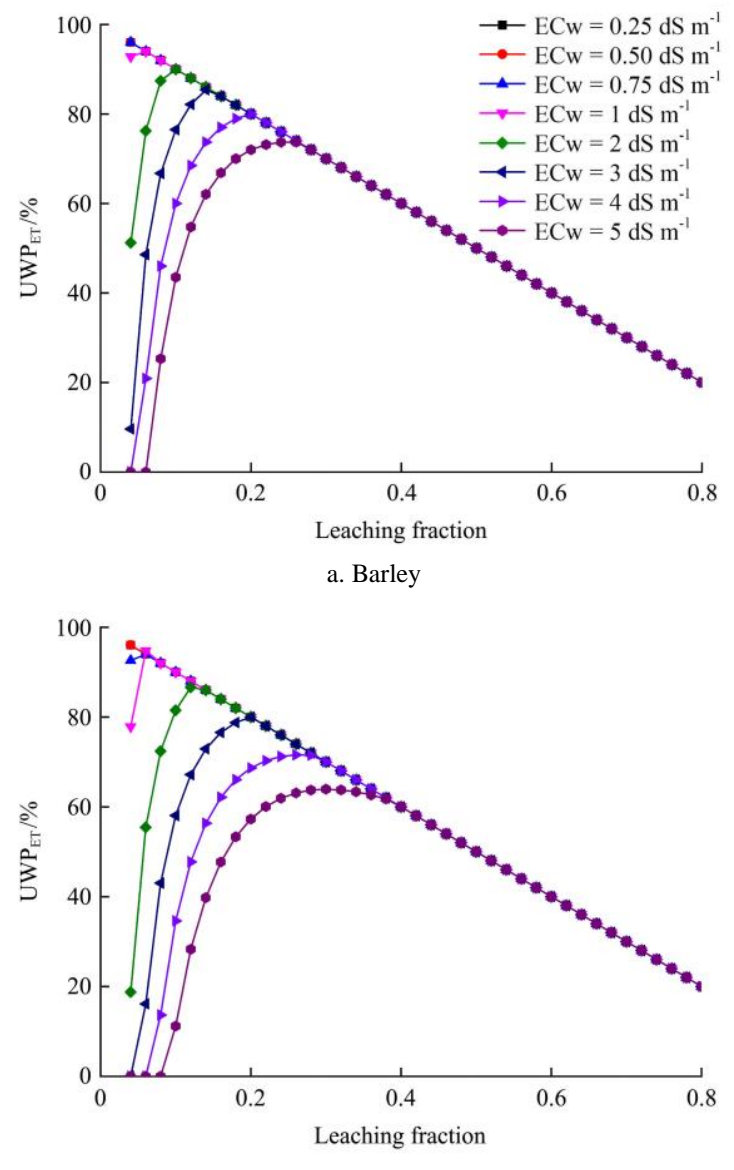

c. Wheat
When the $\mathrm{LF}$ is less than or greater than the $\mathrm{LF}_{3}$ value, Figure 5 shows that the UWP $_{I}$ value could be further improved to maximize the optimized value of LF. The optimal $L F\left(L_{3}\right)$ can be used as an important reference indicator for crops to facilitate the design of irrigation schemes in order to increase the productivity under different irrigation water qualities in areas with limited water resources.

The maximum $\mathrm{UWP}_{\mathrm{I}}$ values decreased and the corresponding optimal $\mathrm{LF}\left(\mathrm{LF}_{3}\right)$ increased gradually as the irrigation water quality increased. For example, when the applied irrigation water had electrical conductivities of $0.25,0.50,0.75,1,2,3,4$, and $5 \mathrm{dS} / \mathrm{m}$, the $\mathrm{UWP}_{\mathrm{I}}^{\prime}$ values for barley were $98.04 \%, 96.15 \%, 96.15 \%$, $94.34 \%, 90.91 \%, 87.09 \%, 83.33 \%$, and $79.06 \%$, respectively. The UWP ${ }_{I}^{\prime}$ values increased as the crop's salt tolerance capacity increased under the same irrigation water quality and LF value.

Furthermore, Figure 4 illustrates the maximum UWP values $\left(\mathrm{UWP}_{\mathrm{I}}^{\prime}\right)$ and optimal LF values $\left(\mathrm{LF}_{3}\right)$ under different irrigation water qualities. There was a linear relationship between $\mathrm{UWP}_{\mathrm{I}}^{\prime}$ and the irrigation water quality for each crop, and another linear relationship between $\mathrm{LF}_{3}$ and the irrigation water quality for each crop. Thus, if the electrical conductivity of the irrigation water is known, the optimal LF values $\left(\mathrm{LF}_{3}\right)$ and maximum unit water productivities $\left(\mathrm{UWP}_{\mathrm{I}}^{\prime}\right)$ can be estimated rapidly and accurately using the corresponding formulas shown in Figure 4. Under different $U_{W W P}$ values, the irrigation water salinity required decreased as the crop's salt tolerance capacity increased. For example, the salinity of the irrigation water should not exceed 5 and $0.75 \mathrm{dS} / \mathrm{m}$ for barley and bean, respectively, to obtain $\mathrm{UWP}_{\mathrm{I}}$ values greater than $80 \%$.
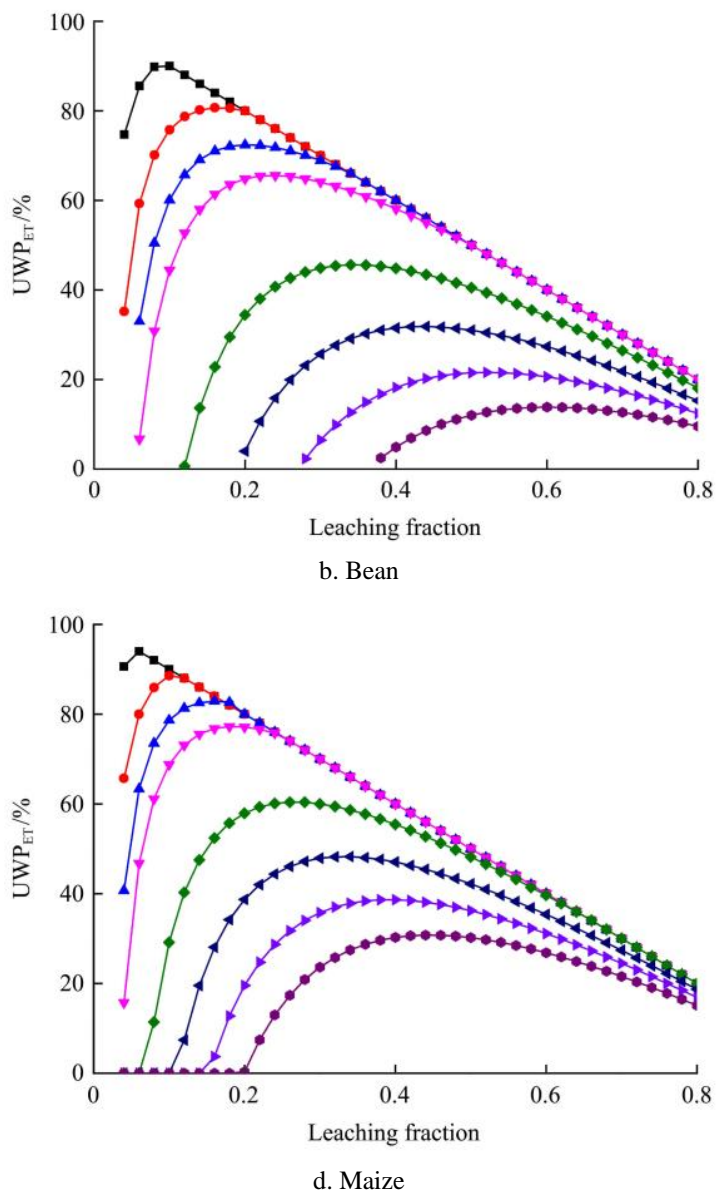

Figure 3 Unit water productivity for crops $\mathrm{ET}\left(\mathrm{UWP}_{\mathrm{ET}}\right)$ and leaching fraction $(\mathrm{LF})$ under different irrigation water salinities $(\mathrm{ECw}=0.25,0.50,0.75,1,2,3,4$, and $5 \mathrm{dS} / \mathrm{m})$ for different crops 

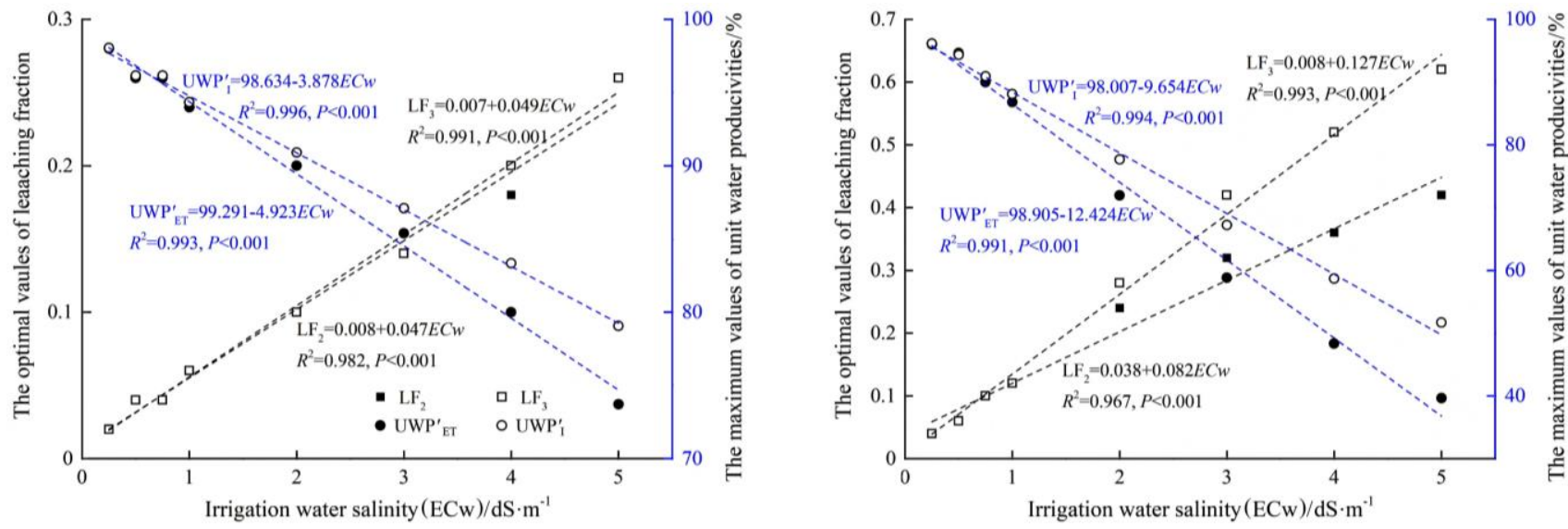

a. Barley

b. Bean
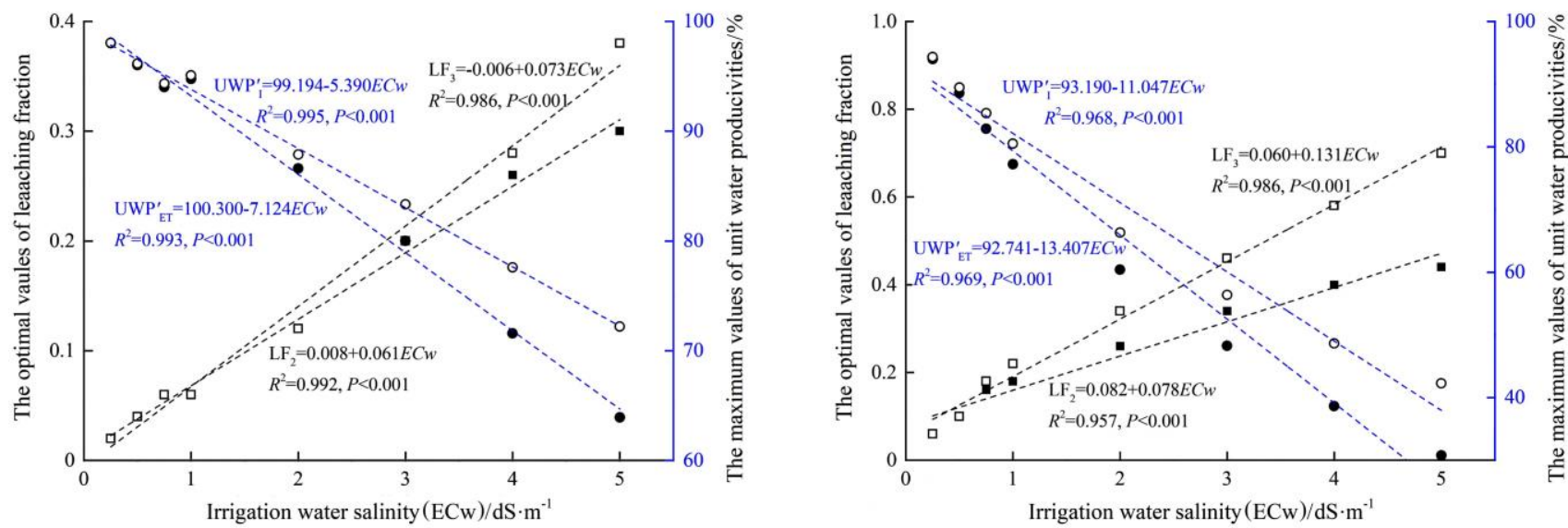

c. Wheat

d. Maize

Figure 4 Maximum unit water productivities $\left(\mathrm{UWP}_{\mathrm{ET}}^{\prime}\right.$ and $\left.\mathrm{UWP}_{\mathrm{I}}^{\prime}\right)$ and their corresponding optimal leaching fractions $\left(\mathrm{LF}_{2}\right.$ and $\left.\mathrm{LF}_{3}\right)$ under different irrigation water salinities $(\mathrm{ECw})$ for different crops
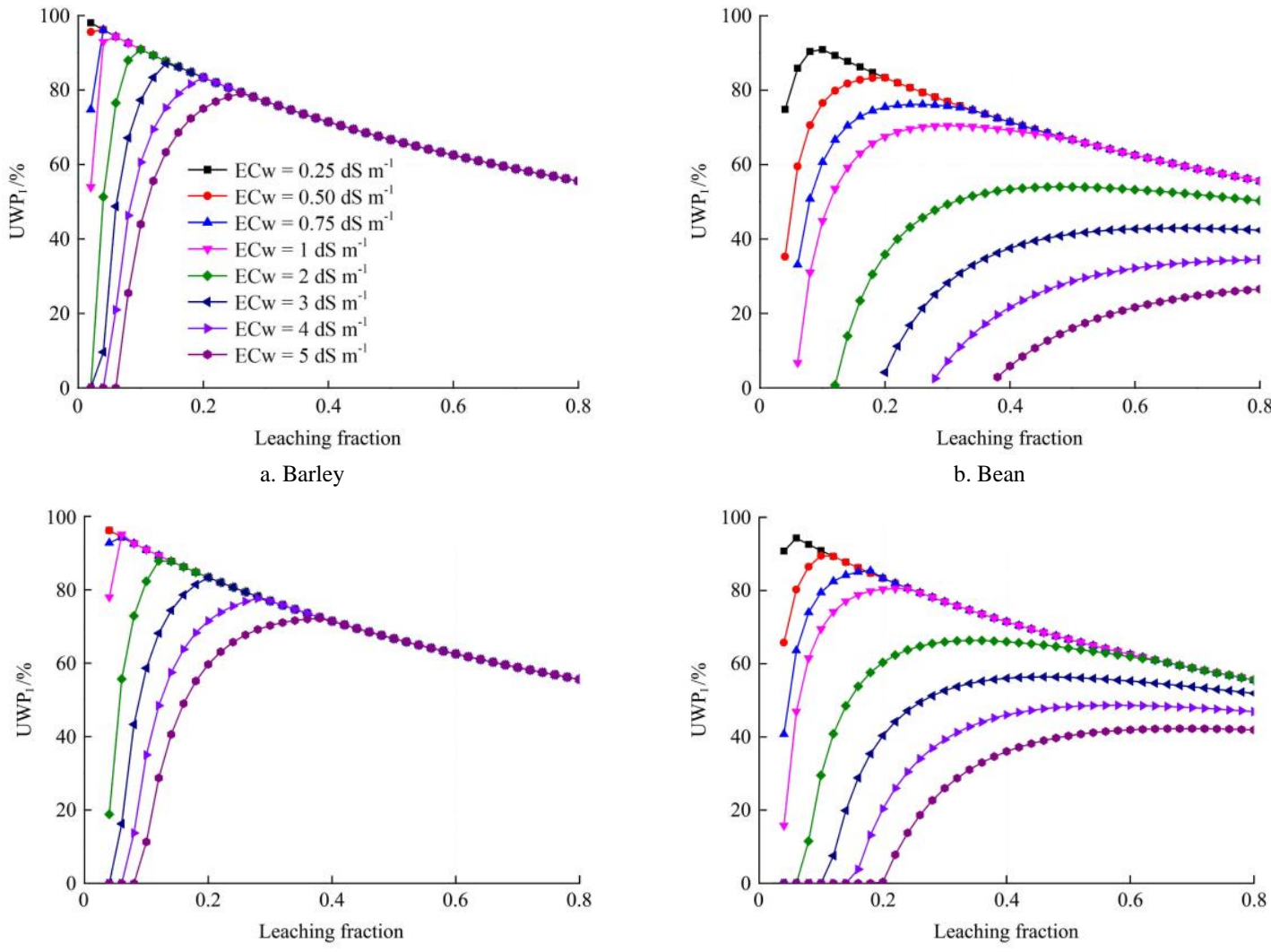

c. Wheat

d. Maize

Figure 5 Unit water productivity for irrigation water $\left(\mathrm{UWP}_{\mathrm{I}}\right)$ and the leaching fraction $(\mathrm{LF})$ under different irrigation water salinities $(\mathrm{ECw}=0.25,0.50,0.75,1,2,3,4$, and $5 \mathrm{dS} / \mathrm{m})$ for different crops 


\subsection{Validation of the theoretical models of UWPs}

A field experiment was conducted previously to assess the effects of LFs on the crop yield (i.e., wheat) when the salinity of the irrigation water was $1350 \mathrm{mg} / \mathrm{L}(E C w=2.11 \mathrm{dS} / \mathrm{m})^{[33]}$. In the previous report by Hoffman et al. ${ }^{[33]}$, field measurements of wheat in terms of the crop ET, irrigation depth, drainage depth, and wheat yield were used to evaluate and validate the proposed theoretical models of the UWPs $\left(U W P_{E T}\right.$ and $\left.U W P_{\mathrm{I}}\right)$ values based on comparisons between the calculated and measured results.

As the $L F$ increased (Table 4), there were clear decreasing trends in the relative errors (REs) between the calculated and measured $R Y$ and $U W P S$ values for wheat. In particular, larger REs between the calculated and measured $R Y$ and $U W P S$ values were achieved under lower LF values (e.g., $L F=0.04$ ). In fact, a lower $L F$ is rarely used in the field due to the greater accumulation of salt and severe declines in the crop yields. Moreover, acceptable $R E s(R E<20 \%)$ between the calculated and measured $R Y$ and $U W P s$ values were achieved under high $L F$ values (e.g., $L F \geq 0.07)$. These results indicated that the theoretical equations (Equations (10) and (11)) are valid for use based on previously reported data, and they could be suitable for application at LF values ranging from 0.07 to 0.17 with acceptable REs.

Table 4 Comparisons between the calculated and measured relative yield $(R Y)$ and UWPs $\left(U W P_{E T}\right.$ and $\left.U W P_{I}\right)$ under different leaching fractions for wheat with irrigation water containing a total dissolved salts concentration of $1350 \mathrm{mg} / \mathrm{L}(\mathrm{ECw}=2.11 \mathrm{dS} / \mathrm{m})$

\begin{tabular}{|c|c|c|c|c|c|c|c|c|c|}
\hline \multirow{2}{*}{$\begin{array}{l}\text { Leaching } \\
\text { fraction* }\end{array}$} & \multicolumn{2}{|c|}{$\mathrm{RY} / \%$} & \multirow{2}{*}{$\mathrm{RE} * / \%$} & \multicolumn{2}{|c|}{$\mathrm{UWP}_{\mathrm{ET}} / \%$} & \multirow{2}{*}{$\mathrm{RE} / \%$} & \multicolumn{2}{|c|}{$\mathrm{UWP}_{\mathrm{I}} / \%$} & \multirow{2}{*}{$\mathrm{RE} / \%$} \\
\hline & calculated & measured & & calculated & measured & & calculated & measured & \\
\hline 0.04 & 12.76 & 58.43 & 78.15 & 12.25 & 57.85 & 78.82 & 12.27 & 56.34 & 78.21 \\
\hline 0.07 & 66.27 & 81.18 & 18.37 & 61.63 & 74.96 & 17.78 & 61.93 & 76.85 & 19.41 \\
\hline 0.09 & 82.12 & 94.51 & 13.11 & 74.73 & 87.40 & 14.49 & 75.34 & 88.07 & 14.45 \\
\hline 0.13 & 99.19 & 96.27 & 3.03 & 86.30 & 83.35 & 3.54 & 87.78 & 84.16 & 4.31 \\
\hline 0.17 & 100 & 100 & 0 & 83 & 81.17 & 2.25 & 85.47 & 83.67 & 2.15 \\
\hline
\end{tabular}

Note: * The leaching fraction values and the corresponding measured yields of wheat were taken from the study by Hoffman et al. ${ }^{[33]}$. $\mathrm{RE}$ is the relative error: $\mathrm{RE}=$ (measured - calculated)/measured $\times 100 \%$

\section{Conclusions}

Each crop (i.e., barley, bean, wheat and maize) reached the maximum RY corresponding to the optimal $\mathrm{LF}\left(\mathrm{LF}_{1}\right)$ for a given irrigation water salinity, and $\mathrm{LF}_{1}$ increased as the irrigation water salinity increased. As the capacity of the crops' salt tolerance decreased, the corresponding optimal leaching fraction $\left(\mathrm{LF}_{1}\right)$ increased when the crops with different salt tolerances all reached the same RY.

The UWPs were increased and then decreased as the LF values increased. Almost every curve between the UWPs and LF for the four crops had an inflection point, and thus the UWPs could be maximized by optimizing the LF under a given irrigation water quality. Crops with high salt tolerance (e.g., barley) could achieve the maximum UWPs $\left(\mathrm{UWP}_{\mathrm{ET}}^{\prime}\right.$ and $\mathrm{UWP}_{\mathrm{I}}^{\prime}$ ) and those with low salt tolerance (e.g., bean) attained the minimum UWPs under specific conditions in terms of the irrigation water quality and LF. According to the linear regression relationships, the maximum UWPs and optimal LFs could all be estimated quickly and accurately based on the salinity of the irrigation water. Under the given value of unit water productivities, the required quality of the irrigation water increased as the capacity of the crops' salt tolerance decreased.

In this study, the theoretical models of the UWPs were validated based on previously reported field experiment data, but the maximum UWPs values and the corresponding optimal LFs were obtained from theoretical calculations under specific irrigation water qualities for the crops. Therefore, a long-term field irrigation experiment should be conducted to verify the use of different irrigation water qualities for each crop.

\section{Acknowledgements}

This research was financially supported by the National Natural Science Foundation of China (Grant Nos. 41830754, U1706211, 41977007, 51679190, 51979220) and National Key R\&D Program of China (Grant Nos. 2016YFC0501401) and Natural Science Foundation of Shaanxi Province (2018JQ5094).

\section{[References]}

[1] Mancosu N, Snyder LR, Kyriakakis G, Spano D. Water scarcity and future challenges for food production. Water, 2015; 7(3): 975-992.

[2] Garcia-Caparros P, Contreras J I, Baeza R, Segura M L, Lao M T. Integral management of irrigation water in intensive horticultural systems of Almería. Sustainability, 2017; 9(12): 2271.

[3] Feng G, Zhang Z, Wan C, Lu P, Bakour A. Effects of saline water irrigation on soil salinity and yield of summer maize (Zea mays L.) in subsurface drainage system. Agricultural Water Management, 2017; 193: 205-213.

[4] Jiang J, Huo Z L, Feng S F, Zhang C B. Effect of irrigation amount and water salinity on water consumption and water productivity of spring wheat in North-west China. Field Crops Research, 2012; 137: 78-88.

[5] Ning S R, Zuo Q, Shi J C, Wang S, Ben-Gal A. Generalization of the root length density distribution of cotton under film mulched drip irrigation. Field Crops Research, 2015; 177: 125-136.

[6] Corwin D L, Grattan S R. Are existing irrigation salinity leaching requirement guidelines overly conservative or obsolete? Journal of Irrigation and Drainage Engineering, 2018; 144(8): 02518001.

[7] Ning S R, Zuo Q, Shi J C. Advances in studying soil water and salt transport in the cotton field with drip irrigation under film in Xinjiang. Journal of Irrigation and Drainage, 2014; 33: 121-125. (in Chinese with English abstract)

[8] Skaggs T H, Anderson R G, Corwin D L, Suarez D L. Analytical steady-state solutions for water-limited cropping systems using saline irrigation water. Water Resources Research, 2014; 50(12): 9656-9674.

[9] Grafton R Q, Williams J, Perry C J, Molle F, Ringler C, Steduto P, et al The paradox of irrigation efficiency. Science, 2018; 361(6404): 748-750.

[10] Ning S R, Zuo Q, Shi J C, Wang S, Liu Z S. Water use efficiency and benefit for typical planting modes of drip-irrigated cotton under film in Xinjiang. Trans. of the CSAE, 2013; 29: 90-99. (in Chinese with English abstract)

[11] Hamdy A, Sardo V, Ghanem K F. Saline water in supplemental irrigation of wheat and barley under rainfed agriculture. Agricultural Water Management, 2005; 78(1-2): 122-127.

[12] Karami Chame S, Khalil-Tahmasbi B, ShahMahmoodi P, Abdollahi A, Fathi A, Seyed Mousavi S J, et al. Effects of salinity stress, salicylic acid and Pseudomonas on the physiological characteristics and yield of seed beans (Phaseolus vulgaris). Sci Agri, 2016; 14(2): 234-238.

[13] Wang Q, Huo Z, Zhang L, Wang J, Zhao Y. Impact of saline water irrigation on water use efficiency and soil salt accumulation for spring maize in arid regions of China. Agricultural Water Management, 2016; 163: $125-138$. 
[14] Dudley L M, Ben-Gal A, Shani U. Influence of plant, soil, and water on the leaching fraction. Vadose Zone Journal, 2008; 7(2): 420-425.

[15] Letey J, Hoffman G J, Hopmans J W, Grattan S R, Suarez D, Corwin D L, et al. Evaluation of soil salinity leaching requirement guidelines. Agricultural Water Management, 2011; 98(4): 502-506.

[16] Tanji K K, Kielen N C. Agricultural drainage water management in arid and semi-arid areas. FAO Irrigation and Drainage Paper No. 61, FAO, Rome, Italy. 2002.

[17] Corwin D L, Rhoades J D, Šimůnek J. Leaching requirement for soil salinity control: Steady-state versus transient models. Agricultural Water Management, 2007; 90(3): 165-180.

[18] Letey J, Feng G L. Dynamic versus steady-state approaches to evaluate irrigation management of saline waters. Agricultural Water Management, 2007; 91(1-3): 1-10.

[19] Ben-Gal A, Ityel E, Dudley L, Cohen S, Yermiyahu U, Presnov E, et al. Effect of irrigation water salinity on transpiration and on leaching requirements: a case study for bell peppers. Agricultural Water Management, 2008; 95: 587-597.

[20] Shani U, Ben-Gal A, Tripler E, Dudley L M. Plant response to the soil environment: An analytical model integrating yield, water, soil type, and salinity. Water Resource Research, 2007; 43: W08418.

[21] Lira R M D, Silva Ê F D F, Simões Neto D E, Santos Júnior J A, Lima B L D C, Silva J S D. Growth and yield of sugarcane irrigated with brackish water and leaching fractions. Revista Brasileira de Engenharia Agrícola e Ambiental, 2018; 22(3): 170-175.

[22] Qiu R, Liu C, Wang Z, Yang Z, Jing Y. Effects of irrigation water salinity on evapotranspiration modified by leaching fractions in hot pepper plants. Scientific Reports, 2017; 7(1): 7231

[23] Qiu R, Yang Z, Jing Y, Liu C, Luo X, Wang Z. Effects of irrigation water salinity on the growth, gas exchange parameters, and ion concentration of hot pepper plants modified by leaching fractions. HortScience, 2018;
53(7): 1050-1055.

[24] Abdulhameed I M. Maximizing irrigation water productivity by optimizing leaching fraction. Journal of Agricultural Science and Technology A, 2017; 7: 73-80.

[25] Molden D, Sakthivadivel R. Water accounting to assesses and productivity of water. International Journal of Water Resources Development, 1999; 15: 55-72.

[26] Maas E V, Hoffman G J. Crop salt tolerance-current assessment Journal of the Irrigation and Drainage Division, 1977; 103(2): 115-134.

[27] Rhoades J D. Reclamation and management of salt-affected soils after drainage. Proc. of the First Annual Western Provincial Conf. Rationalization of Water and Soil Research and Management. Lethbridge, Alberta, Canada, Nov. 29-Dec. 2, 1982.

[28] Rhoades J D, Kandiah A, Mashali A M. The use of saline waters for crop production. FAO Irrigation and Drainage Paper No. 48, FAO, Rome, Italy. 1992.

[29] Abalos D, Jeffery S, Sanz-Cobena A, Guardia G, Vallejo A Meta-analysis of the effect of urease and nitrification inhibitors on crop productivity and nitrogen use efficiency. Agriculture, Ecosystems Environment, 2014; 189: 136-144.

[30] Tilman D. Global environmental impacts of agricultural expansion: the need for sustainable and efficient practices. Proceedings of the National Academy of Sciences, 1999; 96(11): 5995-6000.

[31] Allen R G, Pereira L S, Raes D, Smith M. Crop evapotranspiration guidelines for computing crop water requirements. FAO Irrigation and Drainage Paper No. 56, FAO, Rome, Italy. 1998.

[32] Maas E V. Salt tolerance of plants. Applied Agricultural Research, 1986; 1: 12-26.

[33] Hoffman G J, Rawlins S L, Oster J D, Jobes J A, Merrill S D. Leaching requirement for salinity control. I. Wheat, sorghum, and lettuce. Agricultural Water Management, 1979; 2: 177-192. 